\title{
PENERAPAN TEKNOLOGI INFORMASI DALAM E-TOURISM DANAU BUYAN BERBASIS KEARIFAN LOKAL (E-TOURISM BUYAN, BALI BANGKIT, BALI KEMBALI)
}

(THE APPLICATION OF INFORMATION TECHNOLOGY IN E-TOURISM BUYAN LAKE BASED ON LOCAL WISDOM (E-TOURISM BUYAN, BALI BANGKIT, BALI KEMBALI))

\section{Siti Puspita Hida Sakti MZ', Asslia Johar Latipah'²), Marzuki ${ }^{3)}$}

\author{
1,3) Prodi Sistem Informasi, STMIK Syaikh Zainuddin NW Anjani \\ Jln. Raya Mataram-Lb. Lombok KM. 49 Anjani, Lombok Timur, NTB, 83652 \\ 2) Prodi Teknik Informatika, Fakultas Teknik, Universitas Muhammadiyah Kalimantan Timur \\ Komplek Perguruan Tinggi Muhammadiyah Samarinda, Jl. Ir. H. Juanda No. 15 Samarinda \\ puspita siti@yahoo.co.id ${ }^{1)}{ }_{2}$ marzukiadami@gmail.com $_{2}^{2)}{ }_{2}$ asslia@umkt.ac.id $^{3)}$
}

\begin{abstract}
ABSTRAK
Penelitian ini bertujuan untuk untuk membantu Bali Kembali berbasis pemberdayaan masyarakat melalui penggalian dan pengembangan potensi Danau Buyan, peningkatan keterampilan dan produktivitas usaha pariwisata atau e-tourism Danau Buyan, membangkitkan kemandirian dan membantu menyelesaikan persoalan-persoalan masyarakat sekitar Danau Buyan yang berbasis kearifan lokal di Desa Pancasari. Penelitian akan terus berlanjut karena masih banyaknya potensi-potensi wisata Danau Buyan yang perlu digali dan dikembangkan sebagai wisata baru dan wisata tambahan bagi Bali yang sangat terkenal secara Internasional

Hasil yang ingin dicapai dari penelitian ini adalah: 1) Meningkatnya pengetahuan teknologi informasi di kalangan masyarakat yang bekerja pada bidang pariwisata atau e-tourism di Desa Pancasari, Kecamatan Sukasada, Kabupaten Buleleng, Bali guna keberhasilan usaha pariwisata, sehingga masyarakat terus mendapatkan kebermanfaatan dari segi ekonomi, sosial, budaya, dan kesejahteraan; 2) Pengembangan potensi danau Buyan sebagai aset wisata yang dapat mensejahterakan dan menggunakan stakeholder masyarakat sekitar Danau Buyan dan masyarakat Desa Pancasari; 3) Meningkatkan kerjasama dengan investor guna pengembangan pariwisata Danau Buyan atas dukungan e-tourism Danau Buyan; 4) Pembangunan infrastruktur untuk dukungan e-tourism Danau Buyan sebagai wisata yang masih terus dikembangkan dan sebagai pilihan wisata lain karena berada dekat dengan objek wisata Bedugul, salah satu objek wisata di Bali yang sangat terkenal.
\end{abstract}

Kata kunci: e-tourism, information technology, TWA Danau Buyan

This research aims to help Bali Kembali based on community empowerment through exploring and developing the potential of Buyan Lake, increasing the skills and productivity of the Lake Buyan tourism or e-tourism business, generating independence and helping to solve community problems around Lake Buyan based on local wisdom in Pancasari Village. . Research will continue because of the many tourism potentials of Lake Buyan that need to be explored and developed as new tourism and additional tourism for Bali which is very famous internationally.

The results to be achieved from this research are: 1) Increased knowledge of information technology among people who work in the field of tourism or e-tourism in Pancasari Village, Sukasada District, Buleleng Regency, Bali for tourism efforts, so that people continue to get benefits in terms of economic, social, cultural, and welfare; 2) Developing the potential of Buyan Lake as a tourist asset that can make the welfare of and use stakeholders around Lake Buyan and the people of Pancasari Village; 3) Increasing cooperation with investors to develop Lake Buyan tourism with the support of Lake Buyan e-tourism; 4) Infrastructure development to support Lake Buyan e-tourism as a tourism that is still being developed and as another tourist option because it is close to Bedugul tourist attraction, one of the most famous tourist attractions in Bali.

Keywords: e-tourism, information technology, TWA Danau Buyan 


\section{Pendahuluan}

$\mathrm{P}$ endahuluan menguraikan latar belakang permasalahan yang diselesaikan, isu-isu yang terkait dengan masalah yang diselesaikan, ulasan penelitan yang pernah dilakukan sebelumnya oleh peneliti lain yang relevan dengan penelitian yang dilakukan.

Beberapa tahun belakangan ini, dengan semakin mudahnya mendapatkan informasi dan kemudahan mendapatkan alat transportasi membuat banyak wisatawan melakukan perjalanan. Penggunaan sosial media yang tidak terpisahkan dari kehidupan sehari-hari membuat suatu lokasi wisata dapat menjadi terkenal dan populer hanya dalam hitungan jam. Terlebih bila lokasi wisata tersebut memiliki spot unik dan menarik sehingga hasil photo yang kemudian diupload wisatawan menjadi iklan pariwisata tak berbayar. Suatu lokasi sudah ada dan memiliki banyak pengunjung perlu menambah dan memperbaiki infrastrutur agar wisatawan tidak bosan dan bahkan dapat menambah wisatawan baru. Lokasi wisata baru juga perlu banyak berbenah dan melengkapi infrastruktur agar wisatawan merasa nyaman dan cukup dengan satu lokasi namun memiliki beberapa fasilitas-fasilitas pendukung sehingga wisatawan menjadi betah dan dapat berlama-lama di satu lokasi wisata karena semua hal yang diperlukan saat berlibut di suatu tempat dipermudah dengan tanpa harus perlu keluar dari lokasi wisata tersebut. Pelayanan yang diberikan oleh pengelola tempat wisata juga merupakan suguhan yang wajib ada pada lokasi wisata karena hal tersebut menjadi bagian penting dalam pengembangan pariwisata khususnya yang berbasis kearifan lokal

Seiring makin terkenalnya Bali sebagai daerah wisata, maka beberapa daerah mulai menjadikan pariwisata sebagai Pendapatan Asli Daerah (PAD) yang besar selain sumber daya alam lainnya. Desa Pancasari, Kecamatan Sukasada, Kabupaten Buleleng, Provinsi Bali memiliki Danau Buyan yang dikelilingi hutan dan disebut Taman Wisata Alam (TWA) Danau Buyan. Alam sekitar Danau Buyan dilestarikan oleh masyarakat lokal dengan awig-awig sehingga pemaafaatannya tidak merusak alah dan pengembangan potensi wisatanya membuthkan izin segena amsayarkan dan tetam mengikutsertakan masayarakt dalam pengmbilan keputusan.

Pertemuan desa yang diikuti pimpinan desa dan pengurus lembaga desa, pecalang dan penanggung jawab subak, masyarakat desa, dalam membangun infrastruktur pendukung pariwisata seperti gazebo, homestay, area camping dan pembangunan objek wisata lainnya, harus menghadirkan semua pihak karena dari alam dan untuk alam harus berdasarkan kearifan lokal desa Pancasari dan khususnya masyarakat sekitar danau Buyan.

Masyarakat Pancasari memiliki kearifan lokal berupa sejumlah tradisi, anjuran atau pantangan yang masih berlaku secara turun temurun yang dipraktekkan, dipelihara dan ditaati oleh masyarakat Pancasari. Nilai-nilai lokal yang telah menjadi awig-awig, bukan hanya tentang norma namun ajaran agamapun telah menjadi kebiasaan untuk menjaga alam dan isinya karena bukan hanya manusia yang membuthkan namun hewan dan tumbuhan pun memerlukan keseimbangan alam, Alam yang seimbang menjadi alasan pelestarian kawasan dan dengan menjaga alam, maka manusia dapat hidup dari sumber alam dan kebijaksanaan penggunaan alam.

\section{STUDI PUSTAKA}

E-tourism adalah salah satu bagian dari smart city, merupakan sistem informasi kota yang sangat besar dan kompleks meliputi seluruh sistem yang digunakan pada suatu kota menggunakan mamfaat teknologi informasi atau secara eletronik dan digital. E-toursm danau Buyan desa Pancasari adalah satu bagian dari integrasi smart city yaitu smart village. Kawasan Danau Buyan mrmiliki berbagai potensi sehingga pengembangan kawasan ini masuk dalam Peraturan Daerah guna medukung pariwisata Bali. Bersama dengan Danau Tamblingan, Kawasan Danau Buyan masuk dalam RTBL Kabupaten Buleleng [4]. Baik Smart village maupun e-tourism danau Buyan desa Pancasari memerlukan penelitian lebih lanjut karena membutuhkan banyak informasi seperti dari potensi yang ada, objek atau jenis wisata apa yang perlu dikebangkan, besaran biaya yang diperlukan untuk pembangunannya dan stakeholder-stakholder yang punya peranan penting dalam membangun e-tourism ini diberdayakan. Sehingga dapat mendukung ketercapaian smart city yang sedang digalakkan di Bali. Smart village yang merupakan salah satu bagian smart city tetap membutuhkan dukungan dari Pemerintah, masyarakat sekitar danau Buyan beserta nilai-nilai kearifan lokal, potensi yang dibina dan diberdayakan dari masyarakat lokal seperti yang ditunjukkan pada Gambar 1 [7]. 


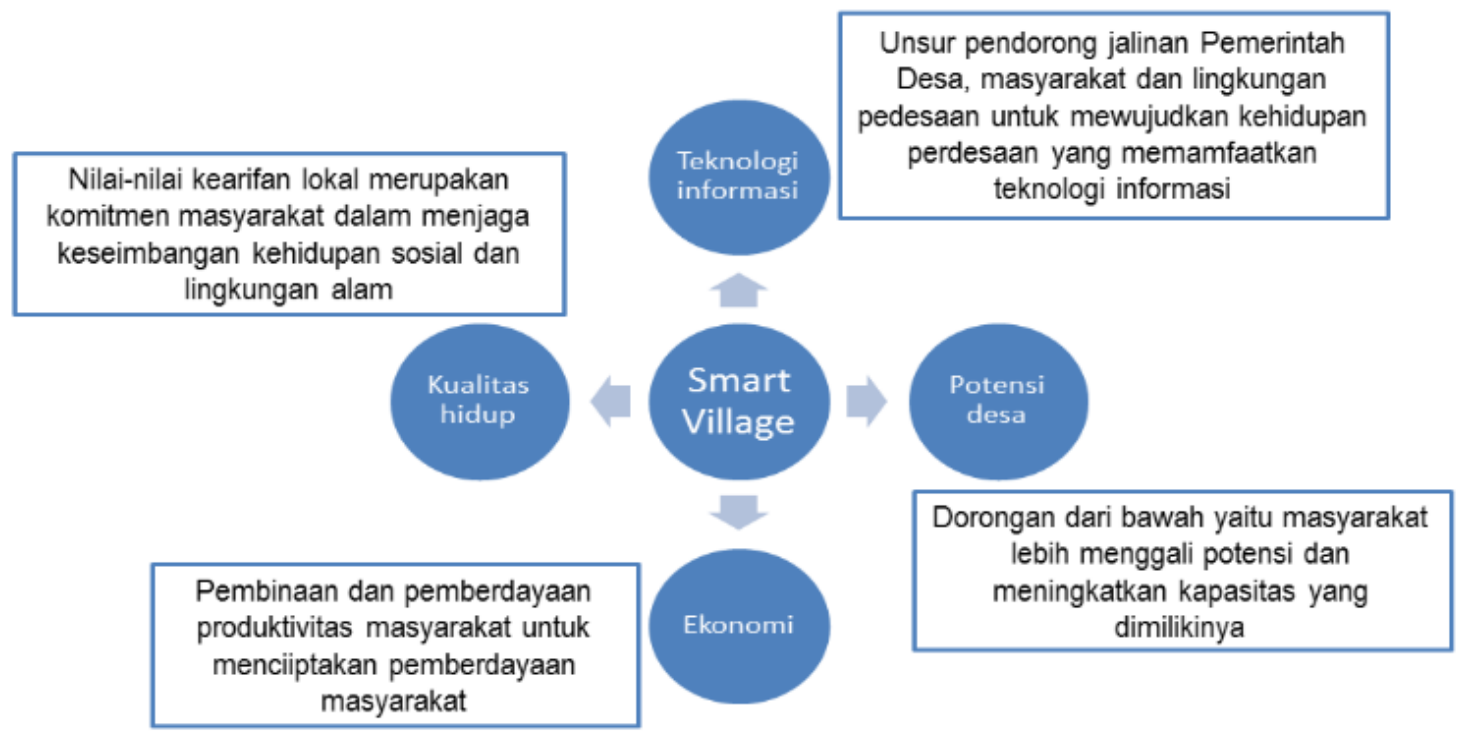

Gambar 1. Model Alternatif Penerapan Konsep Smart Village

\section{Kedudukan hukum dan bentuk kelembagaan}

Kehidupan masyarakat Bali berpedoman pada awig-awig yang dibuat dan disahkan oleh karma masing-masing desa atau desa pakraman. Awigawig digunakan untuk mengatur keserasian manusia dengan Sang Hyang Widhi Wasa, hubungan manusia dengan sesame karma desa, dan hubungan manusia dengan alam. Ketiga hubungan ini merupakan filosofi dari istilah Tri Hita Karana, meliputi aspek Parhyangan, Pawongan dan Palemahan yang saling berkaitan, menjadi sumber kesejahteraan dan kebahagiaan masyarakat.

Masyarakat Bali mengenal dua sistem kelembagaan pemerintah desa, yakni Desa Pakraman dan Desa Dinas. Desa Dinas berfungsi mengatur administrasi pemerintahan sedangkan Desa Pakraman berlandaskan filosofi religius Tri Hita Karana yang didasarkan pada ajaran agama Hindu. Landasan yuridis formal desa Pakraman adalah Undang-undang Dasar Republik Indonesia Tahun 1945 Pasal 18B Ayat 2 tentang Pemerintahan Daerah, Peraturan Daerah Provinsi Bali Nomor 3 Tahun 2003 tentang Perubahan Kedua Perda Provinsi Bali Nomor 3 Tahun 2001 tentang Desa Pakraman.

Fungsi Desa Pakraman adalah urusan adat istiadat dan urusan keagamaan Hindu. Seperti upacara pernikahan, kematian, syukuran, upacara adat, dan pemakaman (Ngaben) Sedangkan Desa Dinas berfungsi mengurus persoalaan administrasi desa terkait dengan pemerintahan diatasnya seperti kecamatan, kabupaten, propinsi dan pusat. Contoh asministrasi tentang kependudukan, pajak bumi dan bangunan, kesehatan, program-program di masyarakat dan lain-lain. Selain desa pakraman dan desa dinar ada juga subak yaitu sebuah organisasi pengairan yang berfungsi dibidang ekonomi.

Secara singkat dapat dikatakan bahwa desa adalah sebuah wilayah bagian kecamatan atau kota ditempati oleh sekumpulan atau kelompok orang secara bersama sama membentuk organisasi kedesaan, yang secara tradisi Bali disebut krama desa [2].

Kabupaten Buleleng adalah salah satu kabupaten di Propinsi Bali yang kaya akan keindahan alam, salah satunya (TWA) Taman Wisata Alam Danau Buyan di Desa Pancasari. TWA Danau Buyan memiliki kawasan hutan dengan salah satu wisata minat khusus yaitu wisata trekking. Pengembangan wisata trekking memerlukan pengetahuan tentang potensi kawasan Hutan TWA Danau Buyan khusunya rute'jalur trekking, identifikasi partisipasi masyarakat agar selaras dengan nilai-nilai kearifan lokal dari sisi sarana prasarana dan rumusan strategis pengembangan wisata trekking kawasan hutan TWA Danau Buyan yang tetap mengikutsertakan stakeholders terkait [5].

E-Tourism atau Electronic Tourism adalah penerapan teknologi informasi pada layanan jasa pariwisata. E-tourism sebagai alternatif masyarakat dalam mengelola objek wisata dan wisatawan dapat mengunjungi objek wisata karena kelengkapan kebutuhan informasi tentang objek wisata, kemudahan akses objek wisata dan pemenuhan sarana prasarana objek wisata. Etourism adalah sebuah sistem berbasis online yang mempermudah wisatawan mendapatkan informasi, 
melakukan reservasi berbagai jenis wisata olahraga, sedangkan pengelola objek wisata mudah mendatangkan wisatawan. Ada tiga unsur yang menjadi prasyarat dari e-tourism yaitu ICT atau teknologi informasi dan komunikasi, pariwisata dan bisnis, serta dukungan dari pemerintah [1]

\section{METODE PENELITIAN}

Metode penelitian merupakan cara ilmiah yang digunakan untuk melakukan suatu penelitian [10]. Metodologi penelitian adalah langkahlangkah sistematik yang digunakan untuk mengejakan atau menyelesaikan suatu masalah. Metode penelitian digunakan sebagai pedoman dalam melaksanakan penelitian agar hasil yang dicapai tidak menyimpang dari tujuan yang ditentukan sebelumnya. Adapun metode penelitian yang dilakukan penulis dalam mengimplementasikan teknologi informasi dalam e-tourism danau buyan berbasis kearifan lokal adalah seperti pada gambar 2 berikut :

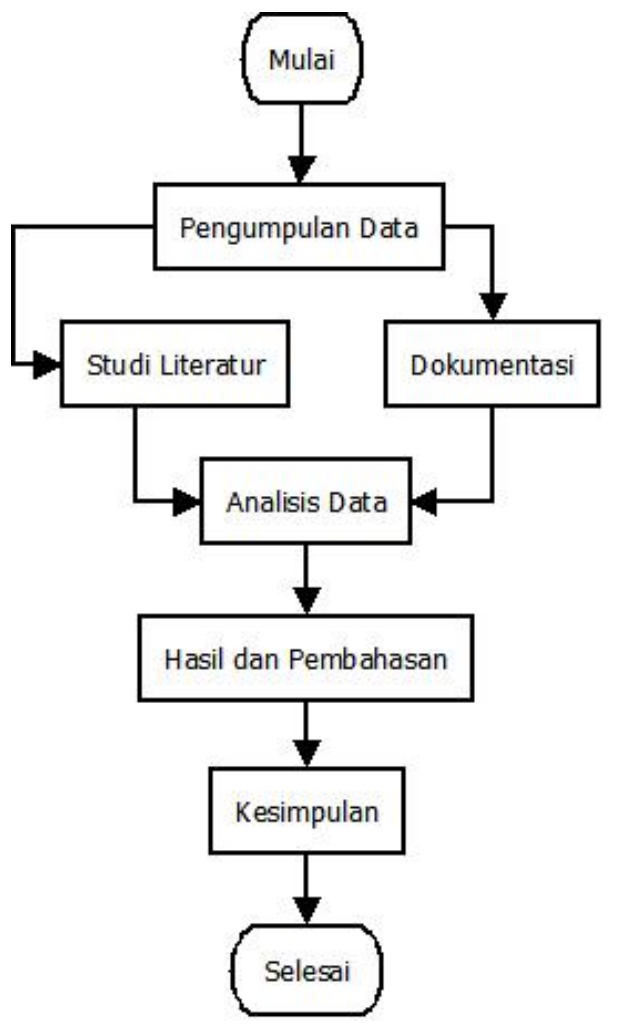

Gambar 2. Metode Penelitian E-Tourism Dana Buyan

1. Pengumpulan Data

a. Studi Literatur. Penulis mengambil data melalui artikel-artikel terkait dan hasil penelitian studi kasus dari jurnal multidisiplin yang memberikan model data dari sudut pandang yang bermacammacam, karena penelitian ini mendukung kearifan lokal masyarakat sekitar danau Buyan, b. Dokumentasi, Penulis mengambil data melalui dokumen-dokumen kebijakan seperti RTRW Prov. Bali termasuk Kawasan Danau Buyan dan Tamblingan dan RTBL Kabupaten Buleleng tentang Kawasan Danau Buyan dan Tamblingan

2. Analisis Data

Dalam tahap ini penulis mengolah data yang telah didapat menjadi informasi, sehingga data yang diperoleh dapat menjadi informasi yang mudah dipahami dan bermanfaat bagi penulis dalam menyelesaikan masalah yang berkaitan dengan penelitian.

Pada penelitian ini, penulis menggunakan data untuk membantu memecahkan masalah yaitu: (1) Data primer adalah data yang diperoleh dari website desa Pancasari, Kecamatan Sukasada, Kabupaten Buleleng, Bali, yang berisi potensi dan produk usaha salah satunya danau Buyan yang dilakukan dengan observasi website, (2) Data sekunder adalah data yang diperoleh melalui studi kepustakaan dengan mempelajari berbagai tulisan melalui buku, jurnal, majalah dan juga internet untuk mendukung penelitian ini.

\section{Hasil dan Pembahasan}

Dalam tahap ini penulis menyusun dan menjelaskan tahapan-tahapan penerapan teknologi informasi dalam implementasi e-tourism danau buyan berbasis kearifan lokal. Bagian ini juga akan menyesuaikan aplikasi-aplikasi di diperlukan untuk mendukung e-tourism danau Buyan berdasarkan potensi-potensi wisata sejalan dengan adat istiadat masyarakat lokal. Strategi pengembangan, rencana dan dampak penelitian ini selalu mengikutsertakan masyarakat dalam semua kegiatan pemberdayaan demi dukungan pembangunan smart city yang dapat dimulai dari salah satunya e-tourism.

\section{HASIL DAN PEMBAHASAN}

A. Peraturan Bupati Buleleng tentang Rencana Tata Bangunan dan Lingkungan Kawasan Danau Buyan dan Tamblingan

"Pasal 1 ayat 13: Rencana Tata Bangunan dan Lingkungan di Kawasan Danau Buyan dan Tamblingan, yang selanjutnya Rencana Tata Bangunan dan Lingkungan (RTBL) di Kawasan Danau Buyan dan Tamblingan adalah panduan bangunan kawasan Danau Buyan dan Tamblingan yang dimaksudkan untuk mengendalikan pemanfaatan ruang, penataan bangunan dan lingkungan, serta membuat materi pokok ketentuan program bangunan dan lingkungan, rencana umum dan panduan rancangan, rencana 
investasi, ketentuan pengendalian rencana, dan pedoman pengendalian pelaksanaan pengembangan Kawasan Danau Buyan dan Tamblingan" [3].

"Bagian Kedua, Konsep Perancangan Kawasan, Pasal 6 [3]:

(1)Penataan daerah daerah puncak (monkey forest) dengan pendekatan "pedestrian precint"

(2) Pengembangan jalur sepanjang jalan utama kawasan sebagai jalur wisata sepeda dan jogging beserta dengan perabot jalan dan sistem penanda

(3) Pengembangan jalur jalur transportasi pertanian untuk memerlancar link and matchkegiatan pertanian dengan kegiatan kepariwisataan

(4) Penataan bangunan komersial dan hunian penduduk secara terintegrasi dengan konsep Low Impact Development".

\section{B. Potensi Taman Wisata Alam Danau Buyan}

1. Kawasan sekitar Danau Buyan dan Danau Tamblingan, Kabupaten Buleleng telah tercantum dalam Peraturan Daerah Provinsi Bali Nomor 3 Tahun 2005 Tentang Rencana Tata Ruang Wilayah Provinsi Bali.

2. Taman Wisata Alam Danau Buyan merupakan salah satu Kawasan Pelestarian Alam yang berfungsi sebagai Taman Wisata Alam (TWA).

3. Kawasan wisata Danau Buyan terletak dekat dengan objek wisata terkenal Bedugul di Desa Pancasari atau Kebun Raya Eka Karya Bedugul.

4. Desa Pancasari memiliki daya tarik wisata alam dan budaya lokal yang dapat dikemas ke dalam berbagai jenis salah satunya wisata olahraga seperti olahraga wisata air, olahraga wisata darat dan olahraga wisata dirgantara. Konsep olahraga pariwisata menunculkan strategi pengembangan pemberdayaan kawasan Danau Buyan sebagai Ikon Sport Tourism Buleleng Bali, yang sesuai dengan kondisi alamnya adalah dengan 2A yaitu attraction (daya tarik wisata) dan amenities (produk fasilitas). Obyek wisata Danau Buyan salah satu ikon olahraga wisata di belahan Bali utara.

5. Kawasan Danau Buyan memiliki keunggulan komparatif yang besar karena memiliki perpaduan antara keindahan danau, hutan dan cuaca yang sejuk serta dikelilingi oleh tempat suci dengan gelombang spiritual tinggi akan filosofi religius Tri Hita Karana, dipegang teguh turun-temurun dan sangat berakar pada masyarakat Bali dengan mayoritas penganut ajaran agama Hindu. Budaya dan agama sebagai satu kesatuan yang tidak terpisahkan pada masyarakat Bali.

6. Ekosistem danau selain bagian dari kegiatan rekreasi dan ekonomi juga ekowisata pendidikan dalam hal pusat penelitian dan pengembangan bidang flora dan fauna. Potensi flora dan fauna berdasarkan hasil Inventarisasi Distribusi Kelimpahan Flora dan Fauna Lahan Basah di kawasan Taman Wisata Alam Danau Buyan - Tamblingan oleh Balai Konservasi Sumber Daya Alam Bali Tahun 2004 tanaman yang ada antara lain: 1). jenis pohon: damar, cemara geseng, beringin, bunut, dll; 2). jenis semak: sia-sia, kalimenje, glagah, jarak, dll; 3). jenis tumbuhan bawah: rumput, tapal kuda, bambu air, sadagori, dll; 4). jenis tumbuhan air: enceng gondok, bulu ayam, ganggang, teratai, dll. Sedangkan jenis fauna yang terdapat di kawasan Taman Wisata Alam Danau Buyan Tamblingan adalah sebagai berikut: 1). aves: mandar batu, elang tikus, sriti, punai, dll; 2). reptilia/mamalia: ular, trenggiling, landak, kijang, dll; 3). insekta: kumbang, lebah, penggerek, semut, dll; 4). biota danau: ikan mujair, tawas, karper, kijing,dll.

\section{Strategi pengembangan produk wisata}

Tabel 1. Strategi Pengembangan produk wisata danau Buyan

\begin{tabular}{|l|l|l|}
\hline No & \multicolumn{1}{|c|}{ Jenis Wisata } & \multicolumn{1}{c|}{ Keterangan } \\
\hline 1. & Wisata Air & $\begin{array}{l}\text { Dibuatkan zona rambu-rambu sepanjang kawasan sebagai tanda kedalaman air } \\
\text { perahu dengan kapasitas } \\
\text { beberapa orang }\end{array}$ \\
\hline a. & $\begin{array}{l}\text { Berperahu menggunakan } \\
\text { kano/perahu tradisional } \\
\text { dengan kapasitas beberapa } \\
\text { orang }\end{array}$ & Dermaga ditempatkan di depan Pura Ulun Danu Buyan \\
\hline
\end{tabular}




\begin{tabular}{|c|c|c|}
\hline b. & Menyelam & $\begin{array}{l}\text { Penyelaman di dampingi pemandu yang profesional, waktu menyelam dibatasi, } \\
\text { zona-zona penyelaman ditentukan untuk menghindari sumber air pada danau } \\
\text { buyan }\end{array}$ \\
\hline c. & $\begin{array}{l}\text { Bersepeda air berbentuk } \\
\text { strowberry }\end{array}$ & $\begin{array}{l}\text { Dermaga ditempatkan di depan pura Ulun Danu Buyan. Dibuatkan sinyal-sinyal } \\
\text { dengan balon warna terang sebagai batas bersepada air }\end{array}$ \\
\hline d. & Memancing & Kolam Pancing Agro Pudak Lestari \\
\hline 2. & \multicolumn{2}{|l|}{ Wisata Alam } \\
\hline a. & Outbond & Ditempuh melalui sistem paket pada jejaring Desa Wisata Pancasari \\
\hline b. & Bersepeda & $\begin{array}{l}\text { Rute: Bali Handara - areal perkebunan - Taman Wisata Alam (TWA) Buyan - } \\
\text { Tanggul Danau Buyan - Pura Ulun Danu - kolam Pancing Agro Pudak Lestari - } \\
\text { kembali ke Bali Handara. }\end{array}$ \\
\hline \multirow[t]{2}{*}{ c. } & Hiking & $\begin{array}{l}\text { (1) Start dari TIC (Tourism Information Centre) - Puri - Agro Wisata - Wisata } \\
\text { Spiritual (Pura Candi Mas dan Pura Pucak Luhur Sari) - TWA Buyan } \\
\text { (2) Jika tidak ingin ke Danau Tamblingan, menggunakan kano/perahu tradisional } \\
\text { sambil berkeliling menikmati indahnya panorama Danau Buyan - Pura Ulun } \\
\text { Danu Buyan - Monkey Forest - Kolam Pancing Agro Pudak Lestari } \\
\text { (3) Kolam Pancing Agro Pudak Lestari - monkey Forest - Pura Ulun Danu Bulian } \\
\text { - berkeliling danau menikmati panorama alam Danau Buyan - Pura Pucak Luhur } \\
\text { Sari - Pura Candi Mas - Agro Wisata - Puri, dilanjutkan makan siang } \\
\text { (4) Berjalan kaki menyusuri tanggul danau. Tanggul-tanggul danau bisa } \\
\text { dibuatkan taman rekreasi untuk tamu beristirahat /memancing dipinggiran danau. }\end{array}$ \\
\hline & Berkendaraan dengan kuda & $\begin{array}{l}\text { TIC (training information centre) - Golf Bali Handara - Pura Candi Mas - Pura } \\
\text { Luhur Sari - Dasong Taman Wisata Alam (TWA) - tanggul danau - Pura Ulun } \\
\text { Danu - kembali ke TIC }\end{array}$ \\
\hline d. & Mendaki gunung & Rute: TWA Buyan - Bukit Lesung - Bukit tapak \\
\hline e. & $\begin{array}{l}\text { Trekking dan jungle } \\
\text { trekking }\end{array}$ & $\begin{array}{l}\text { Potensi unik berupa: sejuknya udara di dalam hutan, keadaan hutan yang masih } \\
\text { alami dengan berbagai jenis pohon, keindahan panorama Danau Buyan dan } \\
\text { tebing-tebing yang curam sepanjang danau }\end{array}$ \\
\hline f. & \multicolumn{2}{|c|}{$\begin{array}{l}\text { zip-line (juga dikenal sebagai flying fox, slide foefie, kawat zip, landasan udara,ropeslide udara, slide kematian } \\
\text { atau trolean persimpangan) }\end{array}$} \\
\hline 3. & \multicolumn{2}{|c|}{ Produk Wisata Fasilitating (Amenities) } \\
\hline & $\begin{array}{l}\text { Pengembangan product } \\
\text { facilitating }\end{array}$ & $\begin{array}{l}\text { 1. Restoran, ruang pertemuan, dan hotel terapung (Rumah Apung) } \\
\text { 2. Rumah Apung bergaya arsitektur tradisional Bali, ramah lingkungan dan } \\
\text { berada diatas danau Buyan } \\
\text { 3. Masakan tradisional Bali: masakan khas ikan air tawar Danau Buyan dengan } \\
\text { sambal strawberry } \\
\text { 4. Usaha kecil (aksesoris-aksesoris), makanan dan minuman khas }\end{array}$ \\
\hline 4. & Produk Wisata Budaya & $\begin{array}{l}\text { 1. Atraksi budaya masyarakat lokal Pancasari yaitu pementasan tarian Barong } \\
\text { 2. Atraksi wisata Sanghyang Penyalin (kesenian Tari) di Desa Pancasari } \\
\text { 3. Peninggalan-peninggalan sejarah zaman dulu seperti benda-benda megalitik } \\
\text { (guci), tempat ibadah umat Hindu (pura) yang berbentuk batu, kegiatan gotong } \\
\text { royong yang ditunjukkan melalui kegiatan subak tradisional }\end{array}$ \\
\hline 5. & Wisata spiritual & Beberapa pura di sekitar Danau Buyan, salah satunya Pura Guna Anyar \\
\hline 6. & Wisata pendidikan & wisata ilmiah/widya wisata dan penelitian \\
\hline
\end{tabular}

\section{Pemberdayaan Masyarakat dan}

\section{Pengembangan Potensi Kawasan Danau Buyan} menuju E-tourism berbasis kearifan lokal

1. Pendampingan pembelajaran konsep-konsep teknologi informasi yang sejalan dan tidak melanggar nilai-nilai kearifan lokal masyarakat Pancasari dalam pengelolaan ekosistem dan pelestarian sumber daya alam serta penelusuran budaya dan tradisi adat.

Kegiatan ini diikuti oleh Pemerintah desa baik Desa Dinas maupun Desa Pakraman, subak, tokoh masyarakat, unsur pemuda, Dinas Pariwisata, pemilik kawasan wisata dan masyarakat sekitar danau Buyan. Metode yang digunakan adalah diskusi dan latihan, dengan menggunakan media audio-visual tentang ekosistem pariwisata pedesaan, mengangkat dan menggali potensi danau Buyan, memperkenalkan tradisi adat dan budaya yang ada. Praktek lapangan dapat dilakukan sebagai latihan pelayanan oleh pemilik dan pengelola wisata kepada dan pengunjung kawasan wisata dengan mengikutsertakan masyarakat sekitar danau Buyan.

Penerapan pengetahuan dan kearifan lokal yang didukung oleh pemahaman teknologi informasi dalam mengembangkan wisata akan berdampak pada penggunaan sumber daya alam 
daerah wisata dengan mempertimbangkan daya dukung sumber daya alam bagi kebutuhan masyarakat Pancasari dan sekitarnya. Ide-ide unik dan menarik menggunakan pengetahuan lokal dan konsep teknologi informasi dapat menjadi salah satu percontohan bagi masyarakat desa lainnya yang memiliki kawasan wisata baru dan menjadi pusat kajian tentang kebudayaan daerah serta kajian kearifan lokal bagi pengelolaan kawasan pariwisata.

2. Pendampingan keterampilan pengolahan sumber daya alam menjadi barang yang bernilai ekonomis namun tetap mempertahankan ekosistem dan kearifan lokal, dapat dijual di kawasan wisata atau tempat tempat lainnya.

Kegiatan ini diikuti ibu-ibu rumah tangga atau para muda-mudi sebagai masyarakat desa Pancasari dan masyarakat danau Buyan dengan memberikan keterampilan mengolah hasil bumi, entah menjadi bahan pangan atau barang yang dapat dijual. Metode yang digunakan adalah praktek keterampilan pembuatan produk pangan dan barang dari alam. Praktek ini didahului dengan pengenalan potensi lokal dan teknologi pembuatan produk. Peserta diberikan pula keterampilan tentang teknik pengemasan produk pangan yang higienis dan baik sehingga dapat dipasarkan. Hasil perikanan danau Buyan dapat menjadi makanan khas yang dapat dijual khusus bagi pengunjung Taman Wisata Alam Danau Buyan.

3. Penataan infrastruktur dan akses menuju lokasi wisata melibatkan pemilik lokasi wisata dan masyarakat di kawasan wisata.

Metode yang digunakan adalah metode partisipatif. Pembangunan infrastruktur pariwisata disesuaikan dengan spot-spot wisata yang ada pada danau Buyan dengan memperhatikan alam. Proyek pembangunannya juga menggunakan tenaga kerja dari lokasi, para guide wisata berasal dari Desa Pancasari karena merekalah yang paling mengenal daerahnya khususnya danau Buyan. Salah satu tujuan penataan infrastruktur adalah meningkatkan efisiensi biaya dalam pembangunan objek wisata dan fasilitas pendukungnya, serta membantu penataan wajah Desa Pancasari sebagai bentuk partisipasi masyarakat Pancasari pada pengembangan pariwisata di desa Pancasari.

4. Pembangunan pusat informasi pemesanan objek wisata termasuk papan penujuk arah dan fasilitas yang ada di masing-masing objek wisata.

Kegiatan ini sudah didahulukan dengan adanya Website desa Pancasari yang memberikan penawaran-penaawan wista air dan wista alam danau Buyan. Kegiatan ini juga perlu diperbanyak karena masih banyak potensi danau Buyan yang perlu digali dan dikembangkan menjadi wisata Desa Pancasari. Dapat menajdi acuan objek wisata Bedugul yang terletak dekat dengan danau Buyan, sehingga pengunjung wisata Bedugul memasukan TWA Danau Buyan sebagai bagian dari perjalanan atau sekedar melipir ke tempat objek-objek wisata baru yang sudah dan sedang dikembangkan di TWA danau Buyan.

5. Penggalian, pengenalan budaya, adat istiadat dan tradisi yang tidak jauh dari Tri Hita Karana.

Perlunya pelatihan seni tari karena salah satu atraksi yang sangat dikenal dari masyarakat Bali. Atraksi ini dapat dijual sebagai wisata budaya dan wisata spiritual. Kegiatan ini juga sebagai wisata pendidikan dengan fokus pengenalan bagi generasi muda untuk tidak lupa akan budaya, memperdalam seni tari dan atraksi lainnya agar tidak ikut tergerus dan dilupakan zaman. Objekobjek wisata spitirutal seperti Pura dan Pemandian Suci di sekitar dan di danau Buyan. Selain sebagai objek wisata tetapi juga sebagai sarana berdoa khususnya untuk pemeluk agama Hindu.

6. Sarana penelitian dan pengabdian penggunaan konsep teknologi informasi berbasis kearifan lokal pada desa pakraman pancasari

Kegiatan ini akan meningkatkan partisipasi dan motivasi masyarakat sekitar danau Buyan pada kegiatan pelestarian sumber daya alam kawasan wisata danau Buyan. Pemerintah Desa dan masyarakat Pancasari dapat menjadi contoh bagi masyarakat di desa sekitar dalam mengelola dan memanfaatkan sumber daya alam wisata baru. Pengembangan pariwisata dengan konsep teknologi informasi dalam e-tourism danau Buyan dapat menjadi salah satu contoh penerapan teknologi informasi pada kawasan wisata Pancasari, menjaga keberadaan mata air sepanjang sungai, juga dapat memberi dampak positif pada perubahan perilaku masyarakat sekitar. Dalam kegiatan ini disiapkan brosur yang berisi infornasi tentang kawasan wisata di desa Pancasari selain yang tertera pada website Desa Pancasari.

7. Meningkatkan kerjasama Pemerintah Desa dengan pengelola wisata dan masyarakat kawasan danau Buyan

Objek wisata yang berada dikawasan danau Buyan, walaupun ada kepemilikan perseorangan namun pengelolaannya harus berdasarkan musyawarah agar tidak timbul polemik dan sengketa. Masyarakat bertanggung jawab akan keamanan dan keberadaan kawasan wisata danau 
Buyan dan mampu membuka peluang kerja serta menaikkan pendapatan desa. Kegiatan ini juga sebagai sarana menyalurkan pendapat pengelola wisata, bertukar pendapat dan ide-ide dengan masyarakat untuk semakin memperkenalkan wisata danau Buyan. Di beberapa objek wisata diperlukan warung-warung kecil yang menjual produk khas daerah dan fasilitas toilet dan mushalla. Tentunya harus disesuaikan dengan kemampuan desa dan batas-batas yang mampu di biayai oleh desa.

Melalui kerjasama ini peningkatan swadaya masyarakat merupakan salah satu dukungan masyarakat untuk desa Pancasari sebagai kawasan pariwisata yang berkonsep teknologi informasi.

\section{E. E-tourism bagian dari Smart City}

Danau Buyan yang terletak di Desa Pancasari merupakan kawasan wisata alam dengan berbagai macam potensi yang didukung oleh kontur wilayah yang terdiri dari lereng gunung dengan banyak mata air dan sungai beraliran besar. Hal ini membuat danau Buyan memiliki berbagai jenis wisata contohnya wisata olahraga. Kehidupan masyarakat desa Pancasari juga tidak jauh dari yang namanya air dan mata air. Dalam kehidupan sehari-hari mereka menggunakan air yang disalurkan dari mata air yang berada hulu desa. Sedangkan kegiatan mandi dan mencuci di lakukang di sungai. Danau Buyan juga memiliki potensi di bidang perikanan.

Pengembangan dan pengelolaan kawasan wisata danau Buyan yang memiliki banyak potensi dapat melahirkan objek-objek atau jenis wisata baru yang belum dikenal masyarakat luas. Namun pengelolaannya perlu diatur dan dibenahi karena gempuran globalisasi yang terkadang tidak sesuai dengan nilai-nilai lokal walaupun rata-rata masyarakat Pancasari telah menggunakan teknologi-teknologi terbaru, bila tidak dibuat aturan atau disesuaikan dengan budaya lokal maka sifat ketimuran yang turun temurun akan tergerus.

Pengembangan Taman Wisata Alam Danau Buyan dengan menggunakan potensi yang ada seperti, wisata alam berupa objek wisata dan kegiatan olahraga, menggunakan produk hasil olahan lokal alam Danau Buyan, menggunakan fasilitas-fasilitas yang tersedia di Danau Buyan, menonton atraksi Danau Buyan dan Desa pancasari, wisata pendidikan dengan melakukan penelitian-penelitian terkait danau Buyan, mengunjungi objek wisata sekitar danau Buyan sebagai tujuan wisata spiritual, dan para wisatawan dapat ikut memperkenalkan TWA Danau Buayan melalui sosial media mereka

Oleh karena itu, penelitian ini sebagai salah satu kegiatan pemberdayaan untuk menggunakan konsep dan prinsip teknologi informasi secara benar dan meningkatkan potensi pariwisata salah satu wisata baru dan membuka peluang kerja serta tetap menjaga ekosistem. Dengan pengetahuan teknologi informasi ini masyarakat Pancasari diharapkan lebih memperkuat praktek dan pengetahuan lokalnya dalam mengelola ekosistem dan sumber daya alam, sehingga kawasan wisata dan ekosistem desa Pancasari dapat dijadikan sebagai daerah resapan air dan jumlah mata air yang banyak tetap dilestarikan serta dapat dimanfaatkan secara berkelanjutan bagi kesejahteraan masyarakat terutama masyarakat Pancasari.

E-tourism sebagai salah satu bagian dari smart city harus mengandung nilai-nilai kearifan lokal masyarakat yang dapat ditunjukkan dalam pengelolaan kawasan, pelestarian bangunan bernilai sejarah, penelusuran budaya dan tradisi berbagai etnis. E-tourism berbasis kearifan lokal dapat digunakan Pemerintah dan masyarakat sebagai bentuk layanan bagi pengelola dan pengunjung lokasi wisata yang dapat berupa informasi lokasi wisata termasuk sosial budaya pada lokasi wisata tersebut serta akses yang mudah dan fasilitas yang memadai akan sangat menarik banyak wisatawan untuk datang berkunjung [6].

\section{Kesimpulan}

Dari hasil dan pembahasan dapat ditarik kesimpulan sebagai berikut:

1. Pendampingan pembelajaran konsep-konsep teknologi informasi yang relevan dengan nilainilai kearifan lokal masyarakat Desa Pancasari dalam pengelolaan ekosistem dan pelestarian sumber daya alam serta penelusuran budaya dan tradisi adat dengan dukungan tingkat Desa Dinas dan Desa Pakraman

2. Pendampingan keterampilan pengolahan sumber daya alam menjadi barang yang bernilai ekonomis namun tetap mempertahankan ekosistem dan kearifan lokal dan dapat dijual di kawasan wisata atau tempat tempat lainnya dengan menyertakan masyarakat desa Pancasari sebagai masyarakat sekitar danau Buyan.

3. Penataan infrastruktur dan akses menuju lokasi wisata sebagai salah satu sarana percepatan 
pembangunan dan perekonomian daerah serta mengapresiasikan kearifan lokal melalui proyek-proyek Pemerintah atas usulan Desa

4. Pembangunan pondok informasi dan penataan display informasi tentang lokasi wisata termasuk papan penujuk arah dan fasilitas yang ada di masing-masing kawasan wisata atas kerjasama kelompok-kelompok masyarakat atau banjar-banjar sekitar danau Buyan

5. Kawsan Danau Buyan dapat menjadi sarana penelitian dan pengabdian yang menggunakan konsep teknologi informasi dan berbasis kearifan lokal dengan dukungan pemerintah dan masyarakat desa.

6. Pengembangan lokasi wisata dengan menambah ide-ide kreatif guna menambah daya tarik wisata dan menjukkan potensi dan produk lokal seperti menjual hasil keterampilan masyarakat dan hasil olahan alam danau buyan.

7. Disarankan pembuatan sistem hasil integrasi dari beberapa sistem detail sehingga informasi yang diberikan kepada wisatawan semakin lengkap.

\section{DAFTAR PUSTAKA}

[1] Kurniawan, A.R., 2020, Tantangan Pengembangan Pariwisata Berbasis Masyarakat Pada Era Digital Di Indonesia (Studi Kasus Pengembangan Pariwisata Berbasis Masyarakat Di Pangalengan), TORNARE Journal of Sustainable Tourism Research, Vol.3 No.1, pp.1-10, Mei 2020, eISSN: 2715-8004

[2] Natalia, V., 2015, Eksistensi Hukum Adat Bali Analisis Konflik Adat Dan Penyelesaiannya Di Desa Pakraman Tabola Sejak Tahun 2008 Sampai Dengan Tahun 2015, Fakultas Hukum Universitas Brawijaya Jl. MT. Haryono, 169 Malang

[3] Peraturan Bupati Buleleng tentang Rencana Tata Bangunan dan Lingkungan di Kawasan Danau Buyan dan Tamblingan Kabupaten Buleleng

[4] Peraturan Daerah Provinsi Bali Nomor 3 Tahun 2005 Tentang Rencana Tata Ruang Wilayah Provinsi Bali kawasan sekitar Danau Buyan dan Danau Tamblingan, Kabupaten Buleleng

[5] Prasiasa, D.P.O., Widari, D.A.D.S, dan Menuh, N., 2019, Pengembangan Wisata Trekking Di Kawasan Hutan Taman Wisata Alam Danau Buyan Kabupaten Buleleng, Jurnal Sosiologi USK Vol.13, No.2, pp.124146, Desember 2019

[6] Sakti MZ, S.P.H. dan Marzuki, 2019, Smart City Pada Pengembangan Pariwisata Kawasan Kota Tua Ampenan Berbasis Kearifan Lokal, JURTI, Vol.3 No.2, pp.165171, Desember 2019, ISSN: 2579-8790

[7] Sakti MZ, S.P.H., Marzuki, dan Latipah, A.J., 2020, Penerapan Teknologi Informasi Dalam Pengembangan Pariwisata Berbasis Smart Village Desa Aikdewa, Jurnal TEKNIMEDIA, Vol.1, No.1, pp.8-17, Mei 2020, DOI: https://doi.org/10.46764/teknimedia.v1i1.8

[8] Sanjaya, P.K.A., Mengakselerasi Pembangunan Ekonomi Daerah Melalui Pariwisata: Pengembangan
Kawasan Danau Beratan Sebagai Objek Wisata Spiritual, PROSIDING - SEMINAR NASIONAL Agama, Adat, Seni dan Sejarah Di Zaman Milenial ISBN: 978-60252255-1-2, Fakultas Ekonomi Universitas Hindu Indonesia

[9] Sudiana, I.K., 2017, Panorama Danau Buyan Berpotensi Sebagai Ikon Olahraga Wisata Nasional, Jurusan Ilmu Keolahragaan, Fakultas Olahraga dan Kesehatan, Universitas Pendidikan Ganesha, Singaraja, Bali

[10] Yanti, D., 2018, Perencanaan Prototipe Sistem Informasi Pariwisata Berbasis Web Di Kabupaten Dairi Sumatera Utara, Jurnal Khasanah Ilmu Vol. 9 No. 2 September 2018, ISSN : 2087-0086 